\title{
Trypanosoma cruzi isolates from Mexican and Guatemalan acute and chronic chagasic cardiopathy patients belong to Trypanosoma cruzi I
}

\author{
Rosario Ruíz-Sánchez, María Paula de León*, Vivian Matta*, Pedro A Reyes, López R**, \\ David Jay, Victor M Monteón**/+
}

\begin{abstract}
Instituto Nacional Cardiología I. Chávez, México DF *Departamento de Citohistología, Facultad de Ciencias Químicas y Farmacia, USAC, Guatemala **Centro de Investigación Enfermedades Tropicales, Patricio Trueba y Regil S/N Universidad Autónoma de Campeche, Campeche, México
\end{abstract}

Trypanosoma cruzi is classified into two major groups named T. cruzi I and T. cruzi II. In the present work we analyzed 16 stocks isolated from human cases and four isolated from triatomines from diverse geographical origins (Mexico and Guatemala). From human cases four were acute cases, six indeterminates, and six from chronic chagasic cardiophatic patients with diagnosis of dilated cardiomyopathy established based on the left-ventricular end systolic dimension and cardiothoracic ratio on chest X-radiography and impaired contracting ventricle and different degree conduction/rhythm aberrations. DNA samples were analyzed based on mini-exon (ME) polymorphism, using a pool of three oligonucleotide for the amplification of specific intergenic region of T. cruzi ME gene.

All the Mexican and Guatemalan isolates regardless their host or vector origin generated a 350 bp amplification product. In conclusion T. cruzi I is dominant in Mexico and Guatemala even in acute and chronic chagasic cardiopathy patients. To our knowledge, this is the first study describing predominance of T. cruzi I in human infection for North and Central America.

Key words Trypanosoma cruzi - mini-exon - Mexico - lineage I - Guatemala

Trypanosoma cruzi is classified into T. cruzi I and T. cruzi II, this denomination aroused from a consensus reached by specialists based on different markers (Satellite Meeting 1999). T. cruzi I is mainly observed in wild mammals and more adapted to marsupials and sylvan triatomines, it is only occasionally isolated from humans, whereas $T$. cruzi II is apparently more associated with primates and it is usually found in human infections. Until now all parasites that have been isolated from seropositive individuals in Brazil belong to T. cruzi II (Fernandes et al. 1998, 1999, Zingales et al. 1998). Recently a published report paper show a predominance of lineage I in 56 Mexican T. cruzi stocks isolated from vectors, humans, and sylvatic mammals using RAPDs, but the clinical status of human cases was not identified (Bosseno et al. 2002). In South-America also was found in 23 isolates from acute chagasic patients using ribosomal and miniexon (ME) marker that $74 \%$ of them belonged to T. cruzi I (Anez et al 2004). It is known that the ME gene is presented in the nuclear genome of all Kinetoplastida in nearly 200 copies in tandemly-repeated sequences. This gene consist of three regions: exon, intron, and intergenic region. The exon is highly conserved, the intron is moder-

+Corresponding author. E-mail: victormonteon@ hotmail.com Received 18 November 2004

Accepted 6 April 2005 ately conserved and the intergenic region or non-transcribed spacer is particular dissimilar. This feature has allowed the classification of $T$. cruzi in two main groups (Devera et al. 2003, Macedo et al 2004).

In the present work we analyzed 16 stocks isolated from human cases and four isolated from triatomines all from with diverse geographic origins (Mexico and Guatemala). Seven came from Guatemala and 13 from Mexico.

Six were isolated from chronic chagasic cardiopathyc (CCC) patients who were evaluated at Instituto Nacional Cardiología "I. Chávez" in Mexico. All of them have been diagnosed with dilated cardiomyopathy based on the leftventricular end systolic dimension, cardiothoracic ratio on chest X-radiography and impaired contracting ventricle and different degree of conduction/rhythm aberrations and five were from indeterminate or blood bank donors, one of them showed an RBBB on his ECG record, four were symptom less subjects and one more from acute case. Two from triatomine vectors. All fourteen isolates came from Mexico.

Out of six Guatemalan isolates, three came from acute cases and one from asymptomatic subject and two from triatomine origin (Table). The CL-Brener strain was used as $T$. cruzi II control.

All parasites were culture in LIT 10\% fetal calf serum enriched medium. The DNA extraction was performed with a mixture of fenol-cloroform-isoamilic alcohol, sodium acetate, and ethanol precipitation. Samples were analyzed based on ME polymorphism, using a pool of three oligonucleotide for the amplification of the intergenic region 
of T. cruzi mini-exon gene: 5'GTGTCCGCCACC TCCTTCGGGCC3' (group 1-specific); 5'CCTGCAGGC ACACGTGTGTGTG3'(group 2-specific); and 5'CCCCCC TCCCAGGCCACACTG 3'(common to group 1 and 2) by PCR as previously reported (Souto et al. 1996). In brief 10 ng of DNA were submitted to amplification in a $50 \mu 1$ of reaction mixture following this thermal profile: $94^{\circ} \mathrm{C} / 1 \mathrm{~min}$; 27 cycles of $94^{\circ} \mathrm{C} / 30 \mathrm{~s}, 55^{\circ} \mathrm{C} / 30 \mathrm{~s}, 72^{\circ} \mathrm{C} / 30 \mathrm{~s} ; 72^{\circ} \mathrm{C} / 10 \mathrm{~min}$. Amplification products were analyzed in $1.5 \%$ agarose gels. T. cruzi I generates a 350 bp product whereas T. cruzi II generates 300 bp product. All the Mexican and Guatemalan isolates regardless their host or vector origin generated a 350 bp amplification product (Fig. 1), consequently all of them belong to $T$. cruzi $\mathrm{I}$ in spite of their broad geographic distribution, since stocks were isolated from individuals living in Northwest of Mexico, Pacific Coast, Central part of Mexico, Gulf of Mexico Coast, including Guatemala. In previous paper it has been reported that Mexican stocks from eight states out of 31 in Mexico belonged to T. cruzi I (Bosseno et al. 2002). Now our data confirm and extend previous findings in addition we disclose $T$. cruzi I may play a major role in human infection in Mexico and Guatemala. Moreover they are involved in CCC as well as acute cases (Table). These results contrast with the situation reported in Brazil, where parasites belonging to $T$. cruzi II are preferentially associated with human infection (Fernades et al. 1999) while T. cruzi I are associated with the sylvatic cycle of the parasite. However, our data is in accordance to recently published paper where $74 \%$ of Venezuelan isolates from acute chagasic patients were typed as T. cruzi I (Anez et al. 2004).

Although, the exact reason to explain these findings is not completely understood, observational data sug-

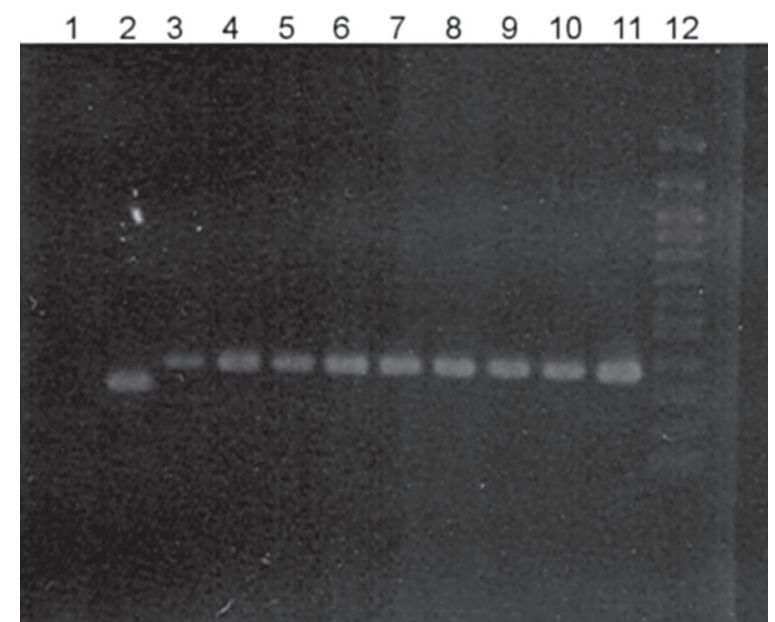

Fig. 1: representative images of polymerase chain reaction products of Mexican and Guatemalan Trypanosoma cruzi isolates with mini-exon primers. Lines - 1: blank; 2: CL-Brener; 3: INC1; 4: INC5; 5: INC-6; 6: INC-7; 7: INC-8; 8: INC-9; 9: H31; 10: H07; 11: TM47; 12: 100 bp leader markers.

gest that $T$. cruzi I predominates in human and sylvatic cycle at least in Mexico and Guatemala.

In order to confirm our results, DNA sequences of PCR amplification products were confirmed by fluorescent DNA sequencing utilizing a Perkin-Elmer Genetic Analyzer 310 DNA sequencer after the agarose DNA fragments were cutt-off from the gel and purified utilizing magnetic micro-beads (Dynal beads) following the manufacture's instructions (data not shown).

TABLE

Main features of Mexican and Guatemalan Trypanosoma cruzi isolates

\begin{tabular}{|c|c|c|c|c|}
\hline $\begin{array}{l}\text { Isolate } \\
\text { name }\end{array}$ & Place and date & $\begin{array}{l}\text { Human clinical } \\
\text { findings }\end{array}$ & $\begin{array}{l}\text { T. cruzi group } \\
\text { mini-exon }\end{array}$ & $\begin{array}{l}\text { Standardized } \\
\text { nomenclature }\end{array}$ \\
\hline INC-1 & Oaxaca, Mex 1994 & AVB, LBBB, VE & I & MHOM/MX/1994/INC1 (T. cruzi I) \\
\hline INC-5 & Veracruz, Mex 1994 & LBBB, VE, VT, CI and cardiomegaly & I & MHOM/MX/1994/INC5 (T. cruzi I) \\
\hline INC-6 & Oaxaca, Mex 2000 & RBBB, CI cardiomegaly & I & MHOM/MX/2000/INC6 (T. cruzi I) \\
\hline INC-7 & Veracruz, Mex 2001 & AVB, VT,VF cardiomegaly & I & MHOM/MX/2001/INC7 (T. cruzi I) \\
\hline INC-8 & Veracruz, Mex 2001 & RBBB, CI and cardiomegaly & I & MHOM/MX/2001/INC8 (T. cruzi I) \\
\hline INC-9 & Guerrero, Mex 2001 & $\mathrm{RBBB}, \mathrm{CI}$ and cardiomegaly & I & MHOM/MX/2001/INC9 (T. cruzi I) \\
\hline INC-10 & Guanajuato, Mex 2002 & Asymptomatic blood donor & I & MHOM/MX/2002/INC10 (T. cruzi I) \\
\hline INC-11 & Hidalgo, Mex 2003 & Asymptomatic blood donor & I & MHOM/MX/2003/INC11 (T. cruzi I) \\
\hline INC-12 & Morelos, Mex 2003 & RIBBB blood donor & I & MHOM/MX/2003/INC12 (T. cruzi I) \\
\hline JJO & Jalisco, Mex & Asymptomatic & I & MHOM/MX/0000/JJO (T. cruzi I) \\
\hline MOR5 & Morelos, Mex & Asymptomatic & I & MHOM/MX/0000/MOR5 (T. cruzi I) \\
\hline $\mathrm{H} 1$ & Yucatan, Mex & Acute case & I & MHOM/MX/0000/H1 (T. cruzi I) \\
\hline Nayarit & Nayarit, Mex & Triatomine & I & PIR/MX/0000/Nayarit (T. cruzi I) \\
\hline CIES & Chiapas, Mex & Triatomine & I & PRX/MX/0000/CIES (T. cruzi I) \\
\hline H38 & Guatemala & Acute case & I & MHOM/GT/0000/H38 (T. cruzi I ) \\
\hline $\mathrm{H} 31$ & Guatemala & asymptomatic & I & MHOM/GT/0000/H31 (T. cruzi I) \\
\hline $\mathrm{H} 7$ & Guatemala & Acute case & I & MHOM/GT/0000/H7 (T. cruzi I) \\
\hline H64 & Guatemala & Acute case & I & MHOM/GT/0000/H64 (T. cruzi I) \\
\hline $\mathrm{T} 1131$ & Guatemala & Triatomine & I & /GT/0000/T1131 (T. cruzi I) \\
\hline T1147 & Guatemala & Triatomine & I & /GT/0000/T1147 (T. cruzi I) \\
\hline
\end{tabular}

AVB: auricule-ventricule blockage; LBBB: left bundle-branch blockage; VE: ventricule extrasystole; VT: ventricule tachycardia; CI: cardiac insuficience; VF: ventricle fibrillation; RBBB: right bundle-branch blockage; RIBBB: right incomplete bundle-branch blockage. 
DNA sequences from each T. cruzi isolated including reference CL-Brener strain confirmed that PCR products corresponded to mini-exon. Although small fragment was sequenced ( 88 to $96 \mathrm{bp}$ ), a BLAST analysis indicates identities between 93 to $97 \%$ in CL Brener respect to Tul 18, $\mathrm{AFI}, \mathrm{CL}, \mathrm{SC} 43, \mathrm{MN}$, and IGRE strains. In the case of Mexican isolates identities were found in the following ranges 88 to $93 \%$ (data not shown).

In conclusion $T$. cruzi $\mathrm{I}$ is dominant in México and Guatemala even in human infections.

\section{ACKNOWLEDGMENT}

To Dr Bertha Espinoza for the donation of Trypanosoma cruzi MOR-5, $\mathrm{H}-1$, and JJO isolates.

\section{REFERENCES}

Anez N, Crisante G, da Silva FM, Rojas A, Carrasco H, Umezawa ES, Stolf AM, Ramirez JL, Teixeira MM 2004. Predominance of lineage I among Trypanosoma cruzi isolates from Venezuelan patients with different clinical profiles of acute Chagas disease. Trop Med Int Health 9: 13191326.

Bosseno MF, Barnabé C, Magallón-Gastelum E, Lozano-Kasten F, Ramsey J, Espinoza B, Breniere SF 2002. Predominance of Trypanosoma cruzi I lineage in Mexico. J Clin Microbiol 40: 627-632.

Devera R, Fernandes O, Coura JR 2003. Should Trypanosoma cruzi be called "cruzi" complex? A review of the parasite diversity and the potential of selecting population after in vitro culturing and mice infection Mem Inst Oswaldo Cruz 98: 1-12.

Fernandes O, Santos Os, Junqueira A, Jansen A, Cupolillo E, Campbell D, Zingales B, Coura JR 1999. Population heterogenity of brazilian Trypanosoma cruzi isolates revealed by the mini-exon and ribosomal spacers. Mem Inst Oswaldo Cruz 94(Suppl. I): 195-197

Fernandes O, Soutto RP, Castro JA, Pereira JB, Ferndes NC, Junqueira AC, Naiff RD, Barret TB, Degrave W, Zingales B, Campbell BA, Coura JR 1998. Brazilian isolates of Trypanosma cruzi from human and triatomomines classificated into two lineages using mini-exon and ribosomal RNA sequence. Am J Trop Med Hyg 58: 807-811.

Macedo A, Machado CR, Oliveira RP, Pena S 2004. Trypanosoma cruzi: genetic structure of population and relevance of genetic variability to the pathogenesis of Chagas disease. Mem Inst Oswaldo Cruz 99: 1-12.

Satellite Meeting 1999. Recommendations from a satellite meeting. Mem Inst Oswaldo Cruz 94(Suppl. 1): 429-432.

Souto R, Fernandes O, Macedo A, Campbell D, Zingales B 1996. DNA markers define two major phylogenetic lineages of Trypanosoma cruzi Mol Bioch Parasitol 83: 141152 .

Zingales B, Souto RP, Mangia RH, Lisboa CV, Campbell DA, Coura JR Jansen A, Fernandes O 1998. Molecular epidemiology of American trypanosomiasis based on dimorphism of rRNA and mini-exon gene sequences. Int J Parasitol 28: 105-112. 
